\title{
Bovine blood neutrophil acyloxyacyl hydrolase (AOAH) activity during endotoxin and coliform mastitis
}

\author{
Jalil MeHRZAD ${ }^{\mathrm{a}, \mathrm{c}}$, Hilde Dosogne ${ }^{\mathrm{b}, \mathrm{c}}$, Bart De SPIEGELEER ${ }^{\mathrm{d}}$, \\ Luc DUCHATEAU ${ }^{\mathrm{c}}$, Christian BURVENICH $^{\mathrm{c} *}$
}

\author{
${ }^{\text {a }}$ Ferdowsi University of Mashhad, Faculty of Veterinary Medicine, Department of Pathobiology, \\ Section Immunology, PO Box 91775-1793, Mashhad, Iran \\ ${ }^{\mathrm{b}}$ DeLaval International AB, Product Portfolio Milk Quality and Animal Health, Industriepark 8-10, \\ 9031 Drongen, Belgium \\ ${ }^{c}$ Ghent University, Faculty of Veterinary Medicine, Department of Physiology and Biometrics, \\ member of Phimadran, Salisburylaan 133, 9820 Merelbeke, Belgium \\ ${ }^{d}$ Ghent University, Faculty of Pharmaceutical Sciences, Drug Quality and Registration (DruQuaR) \\ group, member of Phimadran, Harelbekestraat 72, 9000 Gent, Belgium
}

(Received 7 December 2006; accepted 19 March 2007)

\begin{abstract}
The dynamics of blood neutrophil acyloxyacyl hydrolase (AOAH) activity, the appearance of endotoxin (lipopolysaccharide, LPS) in blood and the role of blood neutrophil AOAH in the severity of Escherichia coli and endotoxin mastitis were investigated in early postpartum dairy cows experimentally challenged with either endotoxin $(n=6)$ or E. coli $(n=6)$. The AOAH activity of blood neutrophils started to decrease significantly at post challenge hours (PCH) 6-24 and 12-24 in the endotoxin and $E$. coli-challenged groups, respectively; it returned to pre-challenged values at PCH 48 in both endotoxin- and E. coli-challenged groups. The cows were classified as moderate and severe responders according to milk production loss in the non-challenged quarters at PCH 48. There were no severe responders in the endotoxin-challenged group. In the E. coli-challenged group, only 1 severe responder was identified. The pre-challenge neutrophil AOAH activity of the severe responder was $\sim 30 \%$ lower than that of moderate responders. No LPS was detected in the plasma of endotoxin-challenged cows; neither was it found in the plasma of moderate responders in the E. colichallenged group at any PCH. However, at PCH 6, a remarkable amount of LPS was detected in the plasma of the severe responder from the E. coli-challenged group. Furthermore, neutrophil AOAH activity was increased by $\sim 70 \%$ in the severe responder at PCH 6 , but it increased by only $\sim 15 \%$ in moderate responders. This was followed by a decreased neutrophil AOAH activity at PCH 12-24 and 24-72 in moderate and severe responders, respectively; the decreased AOAH activity at those $\mathrm{PCH}$ was more pronounced in the severe responder. The pronounced decreased neutrophil AOAH activity during mastitis often coincided with extreme leukopenia, neutropenia and a maximal number of immature neutrophils in the blood. Our results demonstrate that a decrease in neutrophil AOAH activity results in the appearance of LPS in the blood, and low blood neutrophil deacylation activity could be considered as a risk factor for severe clinical coliform mastitis.
\end{abstract}

acyloxyacyl hydrolase (AOAH) / blood / endotoxin / mastitis / neutrophils

* Corresponding author: christian.burvenich@ugent.be 


\section{INTRODUCTION}

An invading pathogen must be held in check by the innate immune system until a specific immune response can be mounted. In the case of Gram negative bacteria, the principal stimulator of the innate immune system is lipopolysaccharide (LPS) or endotoxin, a compound of the bacterial outer membrane. In the udder, this LPS evokes several functional responses in the neutrophils that contribute to the innate immunity of the udder. The recruitment and activation of these short-lived, bone marrow-derived cells to the site of inflammation or infection are pivotal to limit the severity of mastitis [2, 3, 20, 22, 28, 30]. Around calving, the risk for severe clinical mastitis is extremely high; the main underlying reason for this high risk can be impaired blood neutrophil function $[3,22,25]$.

Although LPS has been recognized as an important mediator of local and systemic symptoms during coliform and endotoxin mastitis $[17,20]$, the role of blood neutrophils in defense against LPS during Escherichia coli mastitis is not completely understood. While the presence of LPS in plasma is only short-lasting, its resorption from the mammary gland into the blood stream is possible during E. coli mastitis due to increased permeability of the blood-milk barrier; this triggers a marked increase of tumor necrosis factor alpha (TNF- $\alpha$ ) in the blood. These events are restricted to severely diseased cows [1, 8, 20-22]. Severity of E. coli mastitis seems to be related to the enhanced release of secondary induced inflammatory mediators such as TNF- $\alpha[1,14]$, which could result from impaired LPS detoxification in the blood.

There are many-known and unknown mechanisms, enzymatic and non-enzymatic, that neutralize LPS in the blood $[15,16,18,19]$. Neutrophil granules contain an array of anti-LPS defense proteins such as lactoferrin, lysozyme and bactericidal-permeability increasing protein $[15,16,25]$. The 2-subunit lipase, acyloxyacyl hydrolase (AOAH), which is also present in bovine neutrophil granules [18, 19], hydrolyses and removes the secondary acyl chains of Gram-negative bacterial lipid A of endotoxin [12]; this results in a substantial decreased toxicity of LPS while retaining much of the immunostimulatory potency of native LPS [23]. Blood neutrophil AOAH activity has been found to be decreased in postpartum cows; this decrease was particularly pronounced in some cows, whereas in other cows no changes were observed [8]. Thus, in addition to other antibacterial or anti-LPS defense mechanisms such as the production of reactive oxygen species (ROS) [14, 20, 22], decreased AOAH activity could represent a risk factor for severe clinical coliform mastitis.

Indeed, since LPS is considered as a toxic compound to trigger a massive $\mathrm{TNF}-\alpha$ release [1], and endotoxin shock, decreased LPS detoxification could play a critical role in the outcome of coliform mastitis. To date, no one has demonstrated the changes in neutrophil AOAH activity and plasma LPS concentrations during coliform/endotoxin mastitis. Furthermore, the role of neutrophil AOAH activity as a risk factor for the severity of $E$. coli mastitis in early postpartum dairy cows has not been investigated so far. Therefore, the objectives of the present study were the following: (1) investigate the temporal changes in neutrophil AOAH activity following exposure of the mammary gland to LPS and E. coli; (2) detect LPS in the blood; and (3) relate this with the occurrence of endotoxemia in cattle.

\section{MATERIALS AND METHODS}

This experiment was approved by the Ethics Committee of Ghent University, Faculty of Veterinary Medicine (Belgium). 


\subsection{Experimental animals}

In total 12 healthy Holstein-Friesian cows in their first or second lactation and between 2 and 6 weeks after parturition were used as experimental animals. The animals, on a zero-grazing system from arrival till the end of the experiment, were put into an individual stall and were fed with a special ration for pregnancy and lactation. The cows had calved normally and showed no signs of periparturient diseases. They had free access to water and hay. After gestation, clinically healthy cows showing no signs of typical periparturient diseases were selected on the basis of 2 consecutive bacteriological negative milk samples and a milk somatic cell count (SCC) of $<2.10^{5} / \mathrm{mL}$ milk per individual quarter. One week before the start of the experiment the animals were fed a daily ration of approximately $8 \mathrm{~kg}$ of concentrate and had free access to water and hay. They were milked twice daily at 8 a.m. and 5 p.m. with a 4-quarter milking machine (Packo \& Fullwood, Zeddelgem, Belgium).

\subsection{Induction of mastitis}

In the first study, mastitis was experimentally induced by LPS infusion $(n=6)$ and in the second study, mastitis was induced by infusion of living $E$. coli bacteria $(n=6)$. In the first study, $10 \mathrm{mg}$ LPS from E. coli O111:B4 (Sigma Chemical Co., St. Louis, MO, USA) was diluted in $100 \mathrm{~mL}$ pyrogen-free $(9 \mathrm{~g} / \mathrm{L})$ saline solution and aliquoted in bottles of $5 \mathrm{~mL}$ LPS solution $(500 \mu \mathrm{g}$ in $5 \mathrm{~mL})$. All air was removed from the bottles by a sterile $\mathrm{N}_{2}$-flow. LPS solutions were stored at $-20{ }^{\circ} \mathrm{C}$ until use. Frozen LPS solutions were thawed immediately before a challenge experiment and $15 \mathrm{~mL}$ of pyrogen-free saline solution was added. Before LPS injection the teat ends were disinfected with ethanol (70\%) and mixed with chlorhexidine as previously described [20]. Endotoxin mastitis was induced - after the morning milking - into the left front and hind quarters by a single intramammary (i.mam) injection of $20 \mathrm{~mL}$ LPS solution per quarter ( $25 \mu \mathrm{g} \mathrm{LPS} / \mathrm{mL}$ ), final concentration) using a sterile teat cannula. After injection, each quarter was massaged for $30 \mathrm{~s}$ to distribute the LPS solution in the mammary gland.

In the second study, one hour after the morning milking, $10^{4}$ cfu of $E$. coli $\mathrm{P} 4: 032$ (H37, B-glucuronidase + , haemolysin -) were intramammarily injected into the 2 left udder quarters of each cow. Prior to inoculation, the bacteria had been cultured in Brain Heart Infusion broth (DIFCO Laboratories, Detroit, MI) for $18 \mathrm{~h}$ at $37^{\circ} \mathrm{C}$, washed, resuspended and diluted with sterile $0.01 \mathrm{M}$ phosphate-buffered saline solution (PBS) as previously described $[21,22]$. After cleaning of the udder and sterilization of the teat ends, a total volume of $10 \mathrm{~mL}$ containing $10^{4}$ E. coli $/ \mathrm{mL}$ was injected into the left quarters using a sterile teat cannula; to better observe the signs of clinical mastitis, two quarters were used for the challenge. After injection of the E. coli suspension, each quarter was massaged for $30 \mathrm{~s}$ to distribute the bacteria in the quarters.

\subsection{Blood sampling}

Blood samples for leukocyte counting, differentiation, enumeration and isolation of neutrophils and determination of neutrophil AOAH activity were collected at post challenge hours $(\mathrm{PCH}) 0$, $6,12,24,48,72,144$ and 216 after endotoxin and $E$. coli challenge. A total of $40 \mathrm{~mL}$ blood was collected at each sampling by venipuncture in Vacuette tubes (Greiner ${ }^{\circledR}, 9 \mathrm{~mL}$ ) containing lithium heparin and stored on ice until processed. For LPS quantification in plasma, additional samplings were performed at 
those PCH. To minimize exogenous LPS contamination, samples were collected in a pyrogen-free manner by puncture of the external jugular vein with disposable needles mounted on disposable tubes (Vacutainer $^{\circledR}$, Terumo, Belgium); endotoxin-free vacuum blood collection tubes containing 120 i.u. sodium heparin (Chromogenix AB, Mölndal, Sweden) were used. Plasma samples were frozen at $-20{ }^{\circ} \mathrm{C}$ and stored until use for LPS quantification.

\subsection{Classification of mastitis challenged cows into severe and moderate responders}

Milk production (MP) of individual quarters was measured using a 4-quarter milking machine in order to determine MP in challenged and non-challenged quarters. The MP data from evening and morning milk were pooled to obtain the daily MP. The MP of non-challenged quarters at 2 days after challenge, compared with prechallenge MP, was used for classification of mastitis challenged cows into severe ( $\mathrm{S}$, $\mathrm{MP}<50 \%$ of pre-challenge MP) and moderate $(\mathrm{M}, \mathrm{MP}>50 \%$ of pre-challenge $\mathrm{MP}$ ) responders according to $[7,13,22]$.

\subsection{Blood leukocyte enumeration, neutrophil isolation, preparation and differentiation}

The number of leukocytes in whole blood was determined using an electronic particle counter (Coulter counter Z2, Coulter Electronics, Hialeah, FL, USA) after addition of $200 \mu \mathrm{L}$ of Zap-Oglobin II lytic reagent (Beckman Coulter, Paris, France) to $10^{5}$-fold diluted blood samples and gentle mixing. Neutrophils were isolated from whole blood as previously described [4,20-22]. Double distilled water and buffers used for the isolation procedure were determined to be pyrogenfree using a qualitative limulus amebocyte lysate assay (BioWhittaker Inc., Walkersville, MD, USA). The final pellet of neutrophils was resuspended in $2.5 \mathrm{~mL}$ PBS $(0.01 \mathrm{M})$. The total number of leukocytes in whole blood and isolated blood cells was determined using an electronic particle counter $[20,22]$. The total number of different circulating leukocytes was determined by combination of the total number of blood leukocytes and the differentiation on smear preparations of blood samples [20, 22]. Differential cell counts and staining procedures were performed on whole blood similar to the isolates on eosin-Giemsa-stained (Merck Diagnostica, Darmstadt, Germany) smears, using light microscopy (Nikon labophot-2) at magnification $\times 1000$. Cell identification was based on morphological characteristics as previously described [20,22].

To quantify percentages of each cell type in the samples, a total of 200 cells per slide were classified as neutrophils (mature and immature), monocytes, lymphocytes and eosinophils. The total number of cells isolated was determined by using the cell counter, and the percentage of neutrophils was determined by direct examination. The isolation technique routinely provided large numbers of neutrophils that were determined to be viable by the propidium iodide exclusion method [21] and greater than $95 \%$ neutrophils in content. To prepare neutrophil lysates containing the AOAH enzyme, the isolated neutrophils were lysed with a buffer $(100 \mathrm{mM} \mathrm{KCI}$; $3.9 \mathrm{mM} \mathrm{NaCl} ; 3.5 \mathrm{mM} \mathrm{MgCl} 2 ; 10 \mathrm{mM}$ HEPES (N-2-hydroxyethylpiperazine- N'2-ethanesulfonic acid) ( $\mathrm{pH} 7.4$ ) that contained $1 \%$ (vol/vol) Nonidet P-40, $15 \mathrm{mM}$ EDTA, and $75 \mathrm{~g}$ of phenylmethylsulfonyl fluoride per $\mathrm{mL}$ ). The lysis buffer was added ( $1 \mathrm{~mL} \cdot 10^{-7}$ viable neutrophils), and the cells were incubated at room temperature for $10 \mathrm{~min}$ with frequent mixing; then the mixtures were centrifuged at 
$2000 \times g$ for $10 \mathrm{~min}$. Supernatant aliquots were stored at $-70{ }^{\circ} \mathrm{C}$, for quantification of neutrophil AOAH.

\subsection{Detection of SCC and CFU in challenged quarters}

To examine the dynamics of SCC and $\mathrm{CFU}$ in challenged quarters and to relate these changes to our main findings, milk samples were taken at $\mathrm{PCH} 0,6$, $12,24,48,72,144$ and 216 of the endotoxin and E. coli challenge. The SCC was determined by a Fluoro-optoelectronic cell counting procedure (Fossomatic ${ }^{\circledR} 360$; Foss Electronic, Eden Prairie, MN, USA). The maximal detection capacity of the method for SCC values was $10^{7} / \mathrm{mL}$. The CFU was performed throughout the study, using bacterial plate culture, as previously described [21,22].

\subsection{Neutrophil acyloxyacyl hydrolase (AOAH) activity}

AOAH activity in neutrophil lysates was determined according to McDermott et al. [18, 19], modified by Dosogne et al. [8]. ${ }^{3} \mathrm{H}$ and ${ }^{14} \mathrm{C}$ radioactivity were measured simultaneously with a liquid scintillation counter (1219 Rackbeta, LKB Wallac). $\mathrm{AOAH}$ activity was measured as the radioactivity of ${ }^{3} \mathrm{H}$-labeled fatty acids released from LPS whereas ${ }^{14} \mathrm{C}$ was used for correction of LPS backbone contamination of the fatty acid extracts. AOAH activity was expressed as picomole (pM) fatty acid released per $10^{7}$ neutrophils per hour. All $\mathrm{AOAH}$ determinations were performed in duplicate.

\subsection{Determination of LPS in plasma}

The amount of LPS in plasma was determined using a quantitative limulus amœbocyte lysate (LAL) test (Biowhittaker Inc, Walkersville, Maryland, USA) according to Dosogne et al. [9]. Briefly, one endotoxin unit (EU) per $\mathrm{mL}$ platelet-rich plasma (PRP) corresponds to $100 \mathrm{pg}$ LPS/mL PRP. The LPS detection limit of the assay for bovine plasma was $0.036 \mathrm{EU} / \mathrm{mL}$ PRP. The LPS values were only considered positive when it was higher than 2 times the detection limit; that is, > 0.072 EU/mL PRP or $>7.2 \mathrm{pg} / \mathrm{mL}$ LPS. The results are expressed in $\mathrm{pg} / \mathrm{mL}$.

\subsection{Statistics}

Statistical analysis of the data was performed using a mixed model with the cow as the random effect, time as a categorical fixed effect and milk reduction and its interaction with time as continuous fixed effects. Significance of the differences was determined at $P<0.05^{*}, P<0.01^{* *}$ and $P<0.001^{* * * *}$.

\section{RESULTS}

\subsection{Clinical findings and identification of severe (S) and moderate (M) responders}

Intramammary $E$. coli and LPS provoked clinical signs (both local and systemic) of acute mastitis such as fever, tachycardia, decreased rumen motility and increase of CFU and SCC with decreased MP in all quarters of the cows. The MP in challenged quarters substantially decreased; even at $\mathrm{PCH} 12-54$ it hardly yielded $100 \mathrm{~mL}$ for the experiment (data not shown). This decrease resulted from the damage to the gland caused by both systemic and local effects of mastitis. Most clinical signs peaked at $\mathrm{PCH}$ 6-24 and almost completely restored at $\mathrm{PCH}>72$ (Tab. I).

There were no $\mathrm{S}$ responders when using MP loss of non-challenged quarters 
Table I. Comparison of some circulating leukocytes (WBC), mature neutrophils, immature neutrophils (sum of myelocytes and metamyelocytes) and AOAH (acyloxyacyl hydrolase) activity (pM f.a. $/ 10^{6}$ neutrophils/h) of blood neutrophils and appearance of LPS in serum as well as the SCC and cfu dynamics in inflamed quarters of cows experimentally challenged with LPS $(n=6)$ and $E$. coli (moderate responders; $n=5$, and severe responder; $n=1$ ). $\mathrm{ND}=$ not detected; $\mathrm{PCH}=$ post challenge hours; time $0=$ hour of mastitis induction. The values are means \pm SEM. The significance of the difference between pre and post-infusion of LPS/E. coli is indicated with asterisks $\left({ }^{*} P<0.05\right.$, $* * P<0.01$ and $* * * P<0.001)$.

\begin{tabular}{|c|c|c|c|c|}
\hline \multirow[t]{2}{*}{$\mathrm{PCH}$} & \multirow[t]{2}{*}{ Parameter } & \multirow{2}{*}{$\begin{array}{l}\text { Endotoxin mastitis } \\
\text { group }(n=6)\end{array}$} & \multicolumn{2}{|c|}{ E. coli mastitis group } \\
\hline & & & $\begin{array}{c}\text { Moderate responders } \\
(n=5)\end{array}$ & $\begin{array}{c}\text { Severe responder } \\
(n=1)\end{array}$ \\
\hline \multirow{7}{*}{0} & $\mathrm{WBC} / \mu \mathrm{L}$ & $7314 \pm 213$ & $9633 \pm 658$ & 8540 \\
\hline & Mature neutrophils $/ \mu \mathrm{L}$ & $1903 \pm 80$ & $2886 \pm 290$ & 1708 \\
\hline & Immature neutrophils $/ \mu \mathrm{L}$ & $216 \pm 34$ & $467 \pm 97$ & 256 \\
\hline & LPS in Serum $(\mathrm{pg} / \mathrm{mL})$ & ND & ND & ND \\
\hline & AOAH activity & $73.0 \pm 2.8$ & $70.8 \pm 2.5$ & 56.7 \\
\hline & $\mathrm{SCC} / \mathrm{mL}(\times 1000)$ & $81 \pm 17$ & $86.4 \pm 6.1$ & 71 \\
\hline & $\mathrm{CFU} / \mathrm{mL}(\times 1000)$ & 0 & 0 & 0 \\
\hline \multirow{7}{*}{6} & $\mathrm{WBC} / \mu \mathrm{L}$ & $2368 \pm 299 * * *$ & $5974 \pm 160 * * *$ & 6650 \\
\hline & Mature neutrophils $/ \mu \mathrm{L}$ & $454 \pm 70 * * *$ & $1611 \pm 30 * * *$ & 133 \\
\hline & Immature neutrophils $/ \mu \mathrm{L}$ & $554 \pm 79 * *$ & $636 \pm 67^{*}$ & 532 \\
\hline & LPS in Serum $(\mathrm{pg} / \mathrm{mL})$ & ND & ND & 26 \\
\hline & AOAH activity & $47.9 \pm 2.0 * *$ & $81.0 \pm 7.7 *$ & 92.9 \\
\hline & $\mathrm{SCC} / \mathrm{mL}(\times 1000)$ & $4516 \pm 657$ & $3900 \pm 472$ & 110 \\
\hline & $\mathrm{CFU} / \mathrm{mL}(\times 1000)$ & 0 & $14.1 \pm 11.2$ & 390 \\
\hline \multirow{7}{*}{12} & $\mathrm{WBC} / \mu \mathrm{L}$ & $4442 \pm 1180 * *$ & $2783 \pm 373 * *$ & 8160 \\
\hline & Mature neutrophils / $\mu \mathrm{L}$ & $568 \pm 141^{* * *}$ & $590 \pm 85^{* * *}$ & 82 \\
\hline & Immature neutrophils $/ \mu \mathrm{L}$ & $868 \pm 232 * *$ & $400 \pm 48$ & 979 \\
\hline & LPS in Serum $(\mathrm{pg} / \mathrm{mL})$ & ND & ND & 93 \\
\hline & AOAH activity & $59.8 \pm 2.1 * *$ & $48.6 \pm 4.1 * * *$ & 58.6 \\
\hline & $\mathrm{SCC} / \mathrm{mL}(\times 1000)$ & $>10000$ & $7680 \pm 674$ & 4900 \\
\hline & $\mathrm{CFU} / \mathrm{mL}(\times 1000)$ & 0 & $25.3 \pm 9.4$ & 1400 \\
\hline \multirow{7}{*}{24} & $\mathrm{WBC} / \mu \mathrm{L}$ & $12372 \pm 2125^{* *}$ & $5182 \pm 389 * *$ & 3340 \\
\hline & Mature neutrophils / $\mu \mathrm{L}$ & $1965 \pm 420$ & $988 \pm 110^{* *}$ & 67 \\
\hline & Immature neutrophils $/ \mu \mathrm{L}$ & $2030 \pm 411^{* *}$ & $1138 \pm 137$ & 1536 \\
\hline & LPS in Serum $(\mathrm{pg} / \mathrm{mL})$ & ND & ND & 9.7 \\
\hline & AOAH activity & $65.4 \pm 1.7^{*}$ & $55.4 \pm 8.5^{* * *}$ & 24.6 \\
\hline & $\mathrm{SCC} / \mathrm{mL}(\times 1000)$ & $>10000$ & $4800 \pm 424$ & $>10000$ \\
\hline & $\mathrm{CFU} / \mathrm{mL}(\times 1000)$ & 0 & $8.9 \pm 4.68$ & 420 \\
\hline \multirow{7}{*}{48} & $\mathrm{WBC} / \mu \mathrm{L}$ & $12222 \pm 1244 * *$ & $8944 \pm 236$ & 2580 \\
\hline & Mature neutrophils / $\mu \mathrm{L}$ & $1967 \pm 284$ & $1629 \pm 100^{*}$ & 26 \\
\hline & Immature neutrophils $/ \mu \mathrm{L}$ & $1283 \pm 103 * *$ & $1495 \pm 168 * *$ & 1367 \\
\hline & LPS in Serum $(\mathrm{pg} / \mathrm{mL})$ & ND & ND & $\mathrm{ND}$ \\
\hline & AOAH activity & $70.0 \pm 1.5$ & $72.4 \pm 1.2$ & 18.2 \\
\hline & $\mathrm{SCC} / \mathrm{mL}(\times 1000)$ & $3390 \pm 613$ & $2080 \pm 305$ & $>10000$ \\
\hline & $\mathrm{CFU} / \mathrm{mL}(\times 1000)$ & 0 & $1.9 \pm 0.62$ & 180 \\
\hline
\end{tabular}


Table I. Continued.

\begin{tabular}{|c|c|c|c|c|}
\hline \multirow[t]{2}{*}{$\mathrm{PCH}$} & \multirow[t]{2}{*}{ Parameter } & \multirow{2}{*}{$\begin{array}{l}\text { Endotoxin mastitis } \\
\text { group }(n=6)\end{array}$} & \multicolumn{2}{|c|}{ E. coli mastitis group } \\
\hline & & & $\begin{array}{l}\text { Moderate responders } \\
\qquad(n=5)\end{array}$ & $\begin{array}{c}\text { Severe responder } \\
\quad(n=1)\end{array}$ \\
\hline \multirow{7}{*}{72} & $\mathrm{WBC} / \mu \mathrm{L}$ & $8155 \pm 1656$ & $11315 \pm 464 * *$ & 3560 \\
\hline & Mature neutrophils $/ \mu \mathrm{L}$ & $1360 \pm 305^{*}$ & $2014 \pm 248$ & 36 \\
\hline & Immature neutrophils $/ \mu \mathrm{L}$ & $512 \pm 119^{*}$ & $1349 \pm 167 * *$ & 2100 \\
\hline & LPS in Serum $(\mathrm{pg} / \mathrm{mL})$ & ND & ND & ND \\
\hline & AOAH activity & $72.0 \pm 1.6$ & $96.6 \pm 5.9^{* *}$ & 14.8 \\
\hline & $\mathrm{SCC} / \mathrm{mL}(\times 1000)$ & $1127 \pm 167$ & $867 \pm 297$ & 7950 \\
\hline & $\mathrm{CFU} / \mathrm{mL}(\times 1000)$ & 0 & $0.45 \pm 0.2$ & 35 \\
\hline \multirow{7}{*}{144} & $\mathrm{WBC} / \mu \mathrm{L}$ & $10230 \pm 1317 *$ & $11352 \pm 475^{* *}$ & 7110 \\
\hline & Mature neutrophils $/ \mu \mathrm{L}$ & $1735 \pm 214$ & $1902 \pm 128$ & 995 \\
\hline & Immature neutrophils $/ \mu \mathrm{L}$ & $430 \pm 44 *$ & $1226 \pm 107 * *$ & 1635 \\
\hline & LPS in Serum $(\mathrm{pg} / \mathrm{mL})$ & ND & ND & ND \\
\hline & AOAH activity & $74.3 \pm 1.4$ & $70.7 \pm 4.1$ & 68.7 \\
\hline & $\mathrm{SCC} / \mathrm{mL}(\times 1000)$ & $217 \pm 9$ & $274 \pm 39$ & 5500 \\
\hline & $\mathrm{CFU} / \mathrm{mL}(\times 1000)$ & 0 & 0 & 5.5 \\
\hline \multirow{7}{*}{216} & $\mathrm{WBC} / \mu \mathrm{L}$ & $9055 \pm 246^{*}$ & $10462 \pm 565^{*}$ & 8640 \\
\hline & Mature neutrophils $/ \mu \mathrm{L}$ & $1808 \pm 69$ & $1956 \pm 159$ & 1123 \\
\hline & Immature neutrophils/ $\mu \mathrm{L}$ & $257 \pm 30$ & $818 \pm 84 *$ & 1642 \\
\hline & LPS in Serum $(\mathrm{pg} / \mathrm{mL})$ & ND & ND & ND \\
\hline & AOAH activity & $68.2 \pm 1.4$ & $77.2 \pm 3.2$ & 69.2 \\
\hline & $\mathrm{SCC} / \mathrm{mL}(\times 1000)$ & $107 \pm 12$ & $112 \pm 15$ & 4100 \\
\hline & $\mathrm{CFU} / \mathrm{mL}(\times 1000)$ & 0 & 0 & 5.6 \\
\hline
\end{tabular}

at $\mathrm{PCH} 48$ in the endotoxin-challenged group. In the E. coli-challenged group, 1 cow was identified as an $\mathrm{S}$ responder, whereas the other 5 cows in the $E$. coli model were $\mathrm{M}$ responders. The MP of non-challenged quarters was decreased to $5 \%$ of the pre-challenge MP in the $\mathrm{S}$ cow and extremely low until 5 days after challenge (Fig. 1). In M cows, the MP of non-challenged quarters 2 days after challenge was almost the same volume as the pre-challenge MP and was completely recovered at 3 days after challenge.

\subsection{Blood leukocyte enumeration, differentiation and neutrophil immaturity}

After challenge, both in endotoxin and $E$. coli challenged cows, a transient leukopenia, leukocytosis, neutropenia and neutrophilia was observed (Tab. I). Significant leukopenia was observed between PCH 6 and 12 and 6-24 in endotoxin and $E$. coli mastitis, respectively, regaining, even exceeding, pre-challenge values after those $\mathrm{PCH}$ (Tab. I). Compared to pre-challenged values, the number of circulating mature neutrophils was significantly $(P<0.001)$ minimal at $\mathrm{PCH} 6$ and 12 in endotoxin and E. coli mastitis groups, and in E. coli it still remained significantly low till PCH 48. This decrease often coincided with an increased number of immature neutrophils (metamyelocyte and myelocytes). Blood neutrophil numbers changed significantly over time $(P<0.0001)$. Blood neutrophil numbers decreased significantly with increasing milk reduction $(P=0.050)$. In the $\mathrm{S}$ responder with the highest reduction 


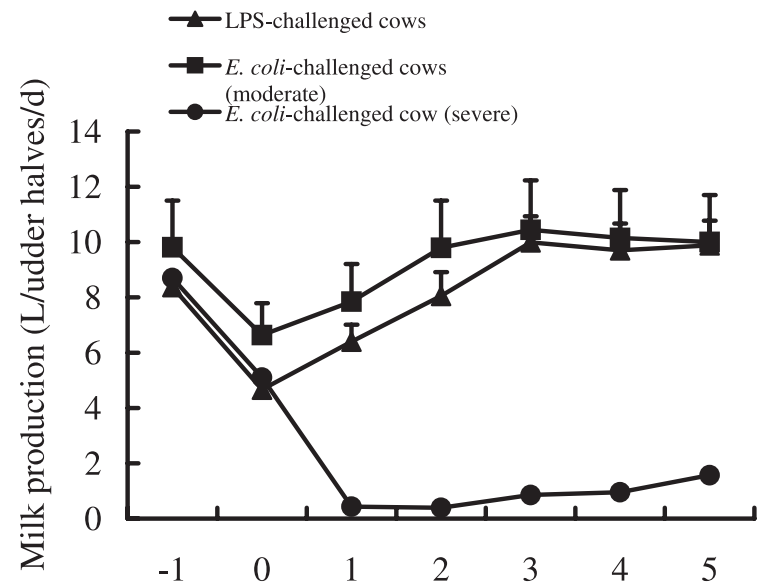

Day relative to mastitis induction
Figure 1. Daily milk production (liters/udder halves) from the non-challenged contralateral quarters from LPS-challenged cows ( $n=6 \pm$ SEM; triangles $)$, $E$. coli-challenged cows (moderate; $n=5 \pm$ SEM; squares) and E. coli-challenged cows (severe; $n=1$; circles) during mastitis. Day $0=$ day of mastitis induction. the decrease was even reached to 133 neutrophils/ $\mu \mathrm{L}$ at $\mathrm{PCH}$. The reduction in blood neutrophil numbers of this cow was severe and remained extremely low between PCH 6 and 72 (less than 5\% of pre-challenged values; Tab. I).

Mature blood neutrophil numbers changed significantly over time $(P<0.0001)$. Mature blood neutrophil numbers decreased significantly with increasing milk reduction $(P=0.002)$. The pattern of decrease in immature neutrophils (metamyelocyte and myelocytes) was remarkable in the $\mathrm{S}$ responder (Tab. I).

\subsection{SCC and CFU in challenged quarters}

The overall pre-challenged SCC was the same for endotoxin, $\mathrm{M}$ and $\mathrm{S}$ groups. In endotoxin challenged quarters, at PCH 12-24 the SCC value exceeded the maximal detection capacity of the method (Tab. I). The SCC in endotoxin and M groups, however, increased faster (maximal at PCH 12). In the $\mathrm{S}$ cow the maximal SCC appeared much later (at $\mathrm{PCH} 24$ ). Throughout the experiment the SCC values did not reach the normal in the S cow (see Tab. I).
In all groups before the experiment, and in the endotoxin group throughout the experiment, the CFU was always zero. The CFU in milk of the $\mathrm{S}$ cow increased much faster (at $\mathrm{PCH}$ 6) and did not reach zero throughout the infection, whereas in $M$ cows it was not substantially increased and it reached zero at $\mathrm{PCH} 144$ and onwards (Tab. I).

\subsection{Blood neutrophil acyloxyacyl hydrolase activity}

Although both groups were moderate responders, the pattern of changes in neutrophil AOAH activity in the endotoxinchallenged group was different from those of the E. coli-challenged (the $\mathrm{M}$ ) group (Tab. I, Fig. 2). After challenge, in the E. coli (M) group, AOAH activity increased (at $\mathrm{PCH} 6 ; P<0.05$ ), then remarkably decreased (at $\mathrm{PCH} 12-24$; $P<0.001$ ), reaching pre-challenged values at $\mathrm{PCH} 48$ and again increased (at $\mathrm{PCH}$ 72; $P<0.001$ ), and finally reached the pre-challenged values; whereas in the endotoxin group, the neutrophil AOAH activity first decreased (at PCH 6-24; $P<0.01$ ) then reached the pre-challenged values at 


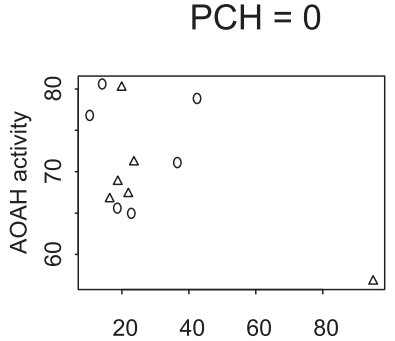

Milk production reduction (\%)
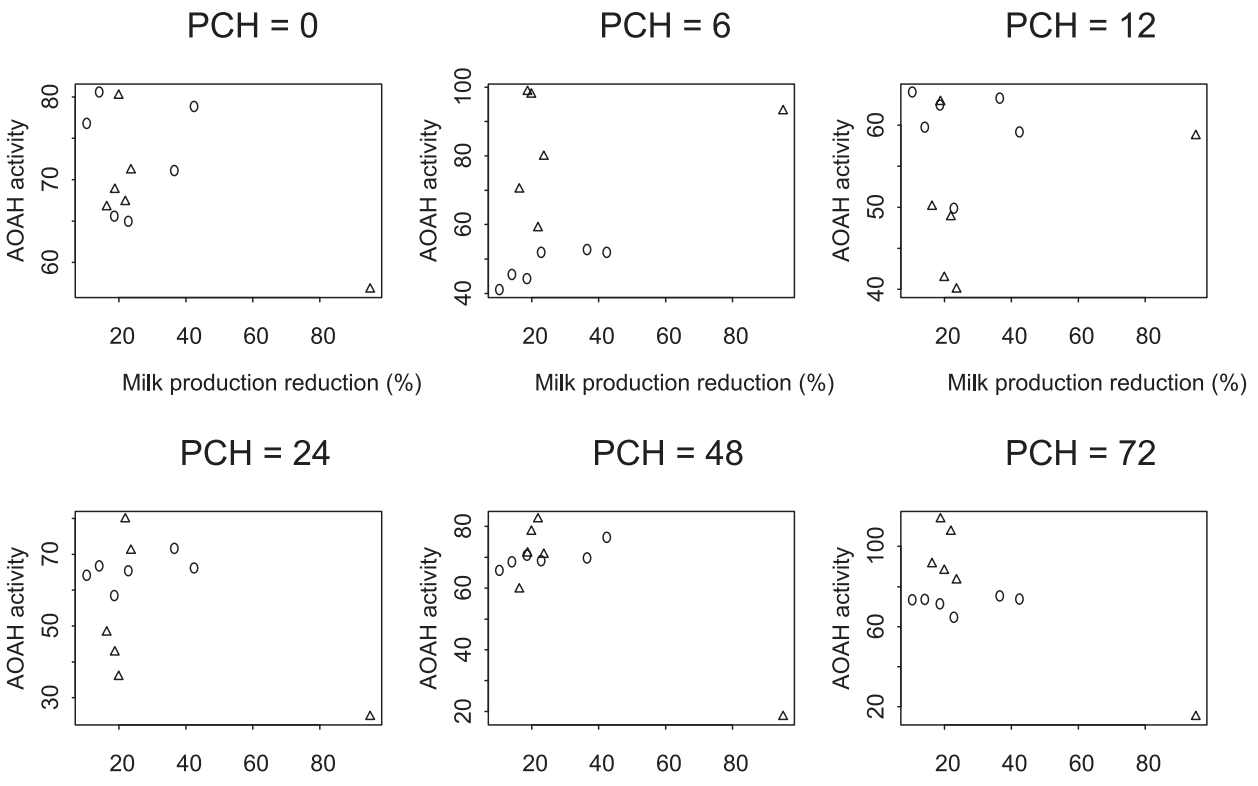

Milk production reduction (\%)
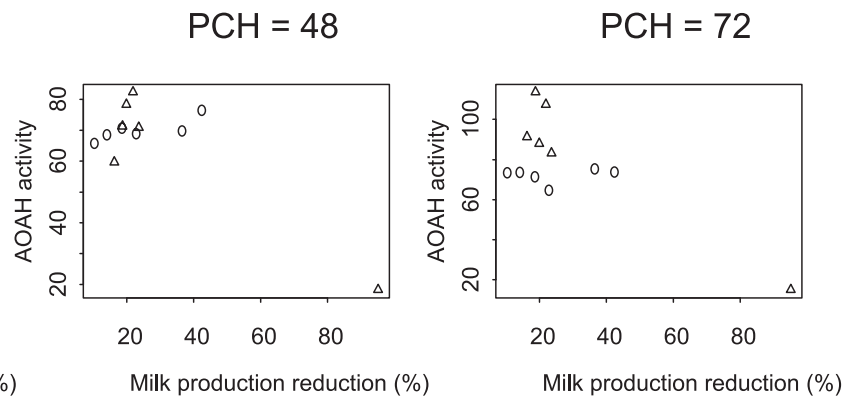

$$
\mathrm{PCH}=216
$$
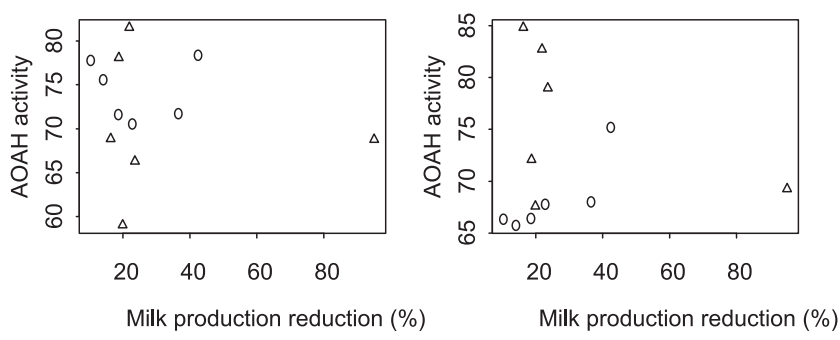

Figure 2. Changes in AOAH activity (pM f.a. $/ 10^{6}$ neutrophils/h) of blood neutrophils and its relation with milk production reduction of non-challenged quarters at 2 days after challenge during experimentally induced endotoxin mastitis ( $n=6$; circles) and E. coli mastitis ( $n=6$; triangles); $\mathrm{PCH}=$ post challenge hours. The triangle, which is located at the most right part of the figures, represents the values for the severe responder.

PCH 48 and onwards (Tab. I, Fig. 2). Therefore, a rebound effect was observed at $\mathrm{PCH} 72$ only in $\mathrm{M}$ cows after reestablishment of blood neutrophil AOAH activity at PCH 48.

Neutrophil AOAH activity changed significantly during infection $(P<0.0001)$. On average neutrophil AOAH activity decreased significantly with increasing milk reduction $(P=0.0004)$. There was, however, also a significant interaction between time and milk reduction $(P<0.0001)$. This was due to the fact that the neutrophil AOAH activity of the severe responder increased dramatically at $\mathrm{PCH}$ 6, reaching pre-challenged values and again hugely decreased (Tab. I), which was not the case for the endotoxin and $\mathrm{M}$ groups. 
Milk reduction increased with lower value of pre-challenged neutrophil $\mathrm{AOAH}$ activity; indeed, before challenge, the neutrophil AOAH activity of the $\mathrm{S}$ responder was $\sim 30 \%$ lower than that of $M$ responders (Tab. I). At PCH 6, neutrophil AOAH activity was increased by $\sim 70 \%$ in the $\mathrm{S}$ responder, which was remarkably different from those of other groups. Overall, throughout the study, the changes on AOAH activity was the most pronounced in the severe responder (Tab. I, Fig. 2).

\subsection{LPS in plasma}

In endotoxin-challenged cows as well as in the E. coli challenged cows (M group), no LPS was detected in the plasma at any time point following intramammary challenge. A remarkable amount of LPS (26, 93 and $9.7 \mathrm{pg} / \mathrm{mL}$ at $\mathrm{PCH} 6,12$ and 24, respectively) was detected in the plasma (Tab. I) but only in the $\mathrm{S}$ cow of the E. coli challenged group.

\section{DISCUSSION}

The major goal of our experiment was to examine the temporal changes on neutrophil deacylation activity and serum LPS concentration during both endotoxin and E. coli mastitis. The fluctuations in blood neutrophil AOAH activity during both endotoxin and E. coli mastitis were consistent with other findings [18, 19]. This study shows, however, a novel-detailed information on temporal changes, especially during the critically earliest stages of mastitis, during which the nature of the cow's innate immune response governs whether and how to eliminate an intramammary infection from the gland [3,22, 28]. In addition, we distinguished between severely and moderately diseased cows based on the MP loss in non-challenged quarters. The MP loss in non-challenged quarters has been shown to be an appropriate parameter to estimate systemic illness during $E$. coli mastitis [2, 7, 13, 21, 22].

Many host-derived cytokines such as interleukin-1 (IL-1), IL-6 [25, 26] and TNF- $\alpha$ [14] are produced during endotoxin/coliform mastitis; they cause systemic effects such as fever and increase the bone marrow output of leukocytes to compensate for the decrease in the circulating pool [20-22]. Consequently, there is a transient increase in the number of circulating immature neutrophils, increased permeability of capillaries and the blood/milk barrier, and a concomitant exudation of some blood proteins in the mammary gland [14,21]. Increased permeability of the blood/milk barrier was indicated by the appearance of clots in milk at PCH 6-24. Between PCH 6 and 24, the influx of a large number of neutrophils in the challenged quarters resulted in a substantial increase of the SCC (see Tab. I). The recruitment of neutrophils into the challenged quarters, as reflected by the SCC, together with their increased functionality [20-22] are both important aspects of the defense mechanism against $E$. coli/endotoxin during coliform mastitis. In this study the two left quarters were injected in order to better assess the signs of clinical mastitis, and the cows' responses to the endotoxin $/ E$. coli challenge would have been less intensive if we had used only one quarter.

The increased milk SCC in challenged quarters coincided with decreased CFU. Although no significant differences on pre-challenged SCC were observed between all groups, the SCC increased much faster in endotoxin and $M$ groups (see Tab. I). This is a classic immunological phenomenon [3,21,22,25] that was more appropriate in endotoxin and $\mathrm{M}$ groups, substantially lessening CFU (Tab. I). The reason why a remarkable amount of LPS was detected at PCH 6-12 would be that at these $\mathrm{PCH}$ there were very low levels of mature neutrophils, and that an array 
of LPS-neutralizing proteins (e.g., cationic peptides) produced by neutrophils may be at low levels due to low numbers of mature neutrophils (see Tab. I, Fig. 2). Furthermore, at those $\mathrm{PCH}$ the extremely rapid/unstoppable increase of CFU (E. coli growth) resulted in a huge imbalance between AOAH and its substrate (LPS) in the $\mathrm{S}$ cow, and the body's AOAH capacity was insufficient to deacylate LPS. Therefore, the initial $E$. coli growth may result in an extremely high LPS production and AOAH-LPS deacylation imbalance. This might result from a far slower increase of SCC in the gland at those PCH (see Tab. I). This exciting topic needs to be further studied.

Local signs of mastitis such as swelling and pain of the challenged quarters, appearance of flecks and milk leakage in challenged quarters were observed at PCH 6 to 24 (data not shown) for all groups. These local signs were more pronounced and prolonged in the S cow, exactly indicating a greater breakdown of the blood-milk barrier in the severe responder, potentially enhancing efflux of LPS to the blood. However, at PCH 48-78, during which the AOAH activity and mature neutrophils were the lowest in this cow, we expected to have detectable LPS, but the LPS was not detected in the blood. The most acceptable reason for these disparities would be the "non-enzymatic substances" in mastitis milk and serum that might contribute to endotoxin neutralization [18, 19,22]. For example, inhibition of neutrophil AOAH activity during natural cases of mastitis caused by both Gram negative and Gram positive organisms $[18,19]$ supports the involvement of nonenzymatic local-and-systemic mediators like LPS binding proteins (LBP), lactoferrin, TNF- $\alpha[1,32]$ in LPS neutralization. Although the LPS molecule is not degraded by, for instance, LBP, the LPS-LBP bond could result in decreased bioavailability of the LPS molecule, thereby reduc- ing the toxic effects of endotoxin during E. coli/endotoxin mastitis. The underlying mechanism of these differences remains to be investigated.

Accordingly $[8,9,18,19]$, before challenge and during early hours of mastitis, the major source of LPS neutralizing factors are predominantly neutrophil AOAH. This might be a decisive factor in deacylation and thereby detoxification of LPS thus prevents prolonged mastitis. Interestingly, before challenge, blood neutrophil AOAH activity was lower in $\mathrm{S}$ than in $\mathrm{M}$ cows. Our data, therefore, suggest decreased LPS detoxification mechanisms. Indeed, in the cow with impaired blood neutrophil AOAH activity before challenge, MP was strongly decreased for several days following intramammary $E$. coli challenge and LPS were detected in plasma, whereas in the other cows MP was restored very rapidly and no LPS were found in plasma. In addition to an impairment of blood neutrophil AOAH activity, the number of blood neutrophil was also drastically decreased in the S cow (see Tab. I), suggesting a further decrease of total LPS detoxification capacity in the blood. The results from our study agreed with other studies $[8,13,22,26,30]$ suggesting that the occurrence of LPS in plasma of severely diseased cows could be the result of a decreased detoxification capacity of blood neutrophils. In our study, it was possible that in $\mathrm{M}$ cows the $E$. coli endotoxins were effectively controlled by milk neutrophil AOAH, though milk neutrophil AOAH activity was not assessed.

The AOAH activity per neutrophil in endotoxin mastitis was also changed, however, the time of the alteration was different from that of the $E$. coli challenged group (see Tab. I, Fig. 2). The rapid decreased neutrophil AOAH activity after LPS challenge in comparison with $E$. coli challenge might be due to a faster inflammatory response caused by intramammary administration of LPS. In contrast, intravenous 
administration of LPS to rabbits resulted in a rapid (within $90 \mathrm{~min}$ ) increase of plasma AOAH activity [10]. So, a different route of LPS administration leads to different temporal changes in neutrophil AOAH activity. Surprisingly, intramammary administration of $E$. coli resulted in faster increased AOAH activity of neutrophils ( $\mathrm{PCH} 6$ ). Therefore, it is possible that, in contrast to endotoxin, live bacteria elicit an increase in AOAH activity in both $\mathrm{M}$ and $\mathrm{S}$ responders immediately after infection. This might be due to the involvement of a phagocytosis phenomenon even by mammary epithelia during maximal immune response which then releases $E$. coli in the tissue, intact [6]. In the LPS model this phenomenon is almost non-existent.

In our study, blood neutrophil AOAH activity was decreased at PCH 12-24 and $6,24-72$ in $\mathrm{M}$ and $\mathrm{S}$ groups, respectively, with a much more pronounced effect in the $\mathrm{S}$ cow. This has not been previously reported. These novel findings could be explained by neutrophil immaturity, since neutrophil granule enzymes are acquired along their maturation pathway $[11,29]$. The release of immature neutrophils during E. coli mastitis was consistent with previous reports $[13,21,22,30]$ and can be ascribed to indirect hematopoietic effects of LPS on the bone marrow. The long-lasting impairment of blood neutrophil AOAH activity in the $S$ cow could be explained by its prolonged shift to the left (intense production of immature neutrophils; see Tab. I).

Together, our findings suggest a direct or indirect stimulatory effect of LPS on blood neutrophil AOAH activity during E. coli mastitis. In the $\mathrm{S}$ cow, intense stimulatory effects were observed very early (PCH 6), whereas in $\mathrm{M}$ cows, despite a mild increase at $\mathrm{PCH} 6$, an intense increase was at a later stage of the inflammation (PCH 72); this could be due to rapid LPS resorption and increased neutrophil immaturity in the $\mathrm{S}$ cow. The rebound effect of neutrophil AOAH activity in $\mathrm{M}$ cows was consistent with previous results $[18,19]$ and can be explained by the stimulatory effect of secondary induced inflammatory mediators. In a previous experiment, the priming effect for enhancement of neutrophil ROS production in $\mathrm{M}$ responders at PCH 72 was tentatively explained by the action of endogenous inflammatory mediators such as interferon-gamma but not LPS $[13,22]$, as in our study. Indeed, enhancement of neutrophil AOAH activity was not observed in the $\mathrm{S}$ cow at $\mathrm{PCH} 72$, during which no LPS was detected in its plasma. Therefore, the impairment of neutrophil AOAH activity at those $\mathrm{PCH}$ can partly be ascribed to extreme neutropenia with increased neutrophil immaturity.

In this study only intracellular AOAH activity of neutrophils was investigated. Therefore, our results might explain the notion that LPS first had to be endocytosed by neutrophils in order for the intracellular AOAH-dependent detoxification (and other LPS detoxification mechanisms) to take place. It is generally accepted that LPB first forms a complex with LPS, which then binds to the CD14 molecule and TLR, especially TLR4, on phagocytes [27]. The $\beta 2$-integrin CD11b/CD18 has also been described as an LPS receptor on bovine neutrophils [24]. Intramammary LPS infusion induced an upregulation of CD11b/CD18 and CD14 on neutrophils $[5,24,30]$ for further LPS recognition. Extracellular AOAH activity was not measured in the present study. Because it has been demonstrated that extracellular and intracelluar AOAH activities of neutrophils show the same trend during induced $E$. coli mastitis [18,19], it may be expected that extracellular AOAH activity also showed the same trends as intracellular neutrophil AOAH activity in our study.

The current study has at least demonstrated that a decreased intracellular neutrophil AOAH activity together with extreme leukopenia, neutropenia and a maximal number of immature neutrophils 
was associated with the occurrence of LPS in plasma, indicating a significant role of not only the quantity of neutrophils, but also, as importantly, the quality of neutrophils (AOAH production capacity) during E. coli mastitis. Besides AOAH, bovine neutrophil granules also contain other LPS binding cationic proteins such as lactoferrin, and a wide variety of cationic peptides and oxidative enzymes that contribute to enhance neutrophil quality and LPS neutralization [15, 16, 21, 22, 31].

In short, this study demonstrates that a decrease in neutrophil AOAH activity results in the appearance of LPS in the blood, and low blood neutrophil deacylation activity could be considered as a risk factor for severe clinical coliform mastitis.

\section{ACKNOWLEDGEMENTS}

This work was supported in part by the Flemish Institute for the Encouragement of Research in the Industry (IWT-grant No. 030784) and the Ferdowsi University of Mashhad.

\section{REFERENCES}

[1] Blum J.W., Dosogne H., Hoeben D., Massart-Leën A.M., Hammon H.M., Bruckmaier R.M., Burvenich C., Tumor necrosis factor-alpha and nitrite/nitrate responses during acute mastitis induced by Escherichia coli infection and endotoxin in dairy cows, Domest. Anim. Endocrinol. (2000) 19:223-235.

[2] Burvenich C., Paape M.J., Guidry A.J., Miller R.H., Heyneman R., Kremer W.D.J., Brand A., Role of the neutrophil leukocyte in the local and systemic reactions during experimentally induced $E$. coli mastitis in cows immediately after calving, Vet. Q. (1994) 16:45-49.

[3] Burvenich C., Van Merris V., Mehrzad J., Diez-Fraile A., Duchateau L., Severity of E. coli mastitis is mainly determined by cow factors, Vet. Res. (2003) 34:521-562.

[4] Carlson G.P., Kaneko J.J., Isolation of leukocytes from bovine peripheral blood, Proc. Soc. Exp. Biol. Med. (1973) 142:853-856.
[5] Diez-Fraille A., Mehrzad J., Meyer E., Duchateau L., Burvenich C., Comparison of L-selectin and Mac-1 expression on blood and milk neutrophils during experimental Escherichia coli-induced mastitis in cows, Am. J. Vet. Res. (2004) 65:1164-1171.

[6] Döpfer D., Almeida R.A., Lam T.J.G.M., Nederbragt H., Oliver S.P., Gaastra W., Adhesion and invasion of Escherichia coli from single and recurrent clinical cases of bovine mastitis in vitro, Vet. Microbiol. (2000) 74:331-343.

[7] Dosogne H., Burvenich C., van Werven T., Roets E., Noordhuizen-Stassen E.N., Goddeeris B., Increased surface expression of $\mathrm{CD} 11 \mathrm{~b}$ receptors on polymorphonuclear leukocytes is not sufficient to sustain phagocytosis during Escherichia coli mastitis in early postpartum dairy cows, Vet. Immunol. Immunopathol. (1997) 60:47-59.

[8] Dosogne H., Capuco A.V., Paape M.J., Roets E., Burvenich C., Fenwick B., Reduction of acyloxyacyl hydrolase activity in circulating neutrophils from cows after parturition, J. Dairy Sci. (1998) 81:672-677.

[9] Dosogne H., Meyer E., Sturk G., Van loon J., Massart-Leen A.M., Burvenich C., Effect of enrofloxacin treatment on plasma endotoxin during bovine Escherichia coli mastitis, Inflamm. Res. (2002) 51:201-205.

[10] Erwin A.L., Munford R.S., Plasma lipopolysaccharide-deacylating activity (acyloxyacyl hydrolase) increases after lipopolysaccharide administration to rabbits, Lab. Invest. (1991) 65:138-144.

[11] Gullberg U., Andersson E., Garwicz D., Lindmark A., Olsson I., Biosynthesis, processing and sorting of neutrophil proteins: insight into neutrophil granule development, Eur. J. Haematol. (1997) 58:137-153.

[12] Hall C.L., Munford R.S., Enzymatic deacylation of the lipid A moiety of Salmonella typhimurium lipopolysaccharides by human neutrophils, Proc. Natl. Acad. Sci. USA (1983) 80:6671-6675.

[13] Heyneman R., Burvenich C., Vercauteren R., Interaction between the respiratory burst activity of neutrophil leukocytes and experimentally induced Escherichia coli mastitis in cows, J. Dairy Sci. (1990) 73:985-994.

[14] Hoeben D., Burvenich C., Trevisi E., Bertoni G., Hamann J., Blum J.W., Role of endotoxin and TNF- $\alpha$ in the pathogenesis of experimentally induced mastitis in periparturient cows, J. Dairy Res. (2000) 67:503-514. 
[15] Levy O., Ooi C.E., Elsbach P., Doerfler M.E., Lehrer R.I., Weiss J., Antibacterial proteins of granulocytes differ in interaction with endotoxin: Comparison of bactericidal/permeability-increasing protein, p15s, and defensins, J. Immunol. (1995) 154:5403-5410.

[16] Levy O., Antibiotic proteins of polymorphonuclear leukocytes, Eur. J. Haematol. (1996) 56:263-277.

[17] Lohuis J.A., Verheijden J.H., Burvenich C., Van Miert A.S., Pathophysiological effects of endotoxins in ruminants, 2. Metabolic aspects, Vet. Q. (1988) 10:117-125.

[18] McDermott C.M., Cullor J.S., Fenwick B.W., Intracellular and extracellular enzymatic deacylation of bacterial endotoxin during localised inflammation induced by Escherichia coli, Infect. Immun. (1991) 59:478-485.

[19] McDermott C.M., Morrill J.L., Fenwick B.W., Deacylation of endotoxin during natural cases of bovine mastitis, J. Dairy Sci. (1991) 74:1227-1234.

[20] Mehrzad J., Dosogne H., Meyer E., Burvenich C., Local and systemic effects of endotoxin mastitis on the chemiluminescence of milk and blood neutrophils in dairy cows, Vet. Res. (2001) 32:131-144.

[21] Mehrzad J., Duchateau L., Burvenich C., Viability of milk neutrophils and severity of bovine coliform mastitis, J. Dairy Sci. (2004) $87: 4150-4162$.

[22] Mehrzad J., Duchateau L., Burvenich C., High milk neutrophil chemiluminescence limits severity of bovine coliform mastitis, Vet. Res. (2005) 36:101-116.

[23] Munford R.S., Hall C.L., Detoxification of bacterial lipopolysaccharides (endotoxins) by a human neutrophil enzyme, Science (1986) 234:203-205.

[24] Paape M.J., Lilius E.M., Wiitanen P.A., Kontio M.P., Miller R.H., Intramammary defense against infections by Escherichia coli, Am. J. Vet. Res. (1996) 57:477-482.
[25] Paape M., Mehrzad J., Zhao X., Detilleux J., Burvenich C., Defense of the bovine mammary gland by polymorphonuclear neutrophil leukocytes, J. Mammary Gland Biol. Neoplasia (2002) 7:109-121.

[26] Shuster D.E., Lee E.K., Kehrli M.E., Bacterial growth, inflammatory cytokine production, and neutrophil recruitment during coliform mastitis in cows within ten days after calving, compared with cows at midlactation, Am. J. Vet. Res. (1996) 57:15691575.

[27] Tobias P.S., Ulevitch R.J., Lipopolysaccharide binding protein and CD14 in LPS dependent macrophage activation, Immunobiology (1993) 187:227-232.

[28] Vandeputte-Van Messom G., Burvenich C., Roets E., Massart-Leën A.M., Heyneman R., Kremer W.D.J., Brand A., Classification of newly calved cows into moderate and severe responders to experimentally induced Escherichia coli mastitis, J. Dairy Res. (1993) 60:19-29.

[29] Van Merris V., Meyer E., Burvenich C., Functional maturation during bovine granulopoiesis, J. Dairy Sci. (2002) 85:28592868.

[30] Van Werven T., Noordhuizen-Stassen E.N., Daemen A.J.J.M., Schukken Y.H., Brand A., Burvenich C., Preinfection in vitro chemotaxis, phagocytosis, oxidative burst, and expression of CD11/CD18 receptors and their predictive capacity on the outcome of mastitis induced in dairy cows with Escherichia coli, J. Dairy Sci. (1997) 80:67-74.

[31] Wang D., Pabst K.M., Aida Y., Pabst M.J., Lipopolysaccharide-inactivating activity of neutrophils is due to lactoferrin, J. Leukoc. Biol. (1995) 57:865-874.

[32] Zimecki M., Spiegel K., Wlaszczyk A., Kubler A., Kruzel M.L., Lactoferrin increases the output of neutrophil precursors and attenuates the spontaneous production of TNF-alpha and IL-6 by peripheral blood cells, Arch. Immunol. Ther. Exp. Warsz. (1999) 47:113-118. 